\title{
Screening of Lentil (Lens culinaris Medikus sub sp. culinaris) Germplasm against Fusarium Wilt (Fusarium oxysporum f. sp. lentis)
}

\author{
Jitendra Kumar Meena ${ }^{1 *}$, Akanksha Singh ${ }^{1}$, H.K. Dikshit ${ }^{1}$, G.P. Mishra ${ }^{1}$, M. Aski ${ }^{1}$, \\ N. Srinivasa ${ }^{2}$, Soma Gupta ${ }^{1}$, Deepa Singh ${ }^{1}$ and Aparna Tripathi ${ }^{1}$ \\ ${ }^{1}$ Division of Genetics, Indian Agricultural Research Institute, Pusa, New Delhi, India \\ ${ }^{2}$ Division of Plant Pathology, Indian Agricultural Research Institute, Pusa, New Delhi, India \\ *Corresponding author
}

\section{A B S T R A C T}

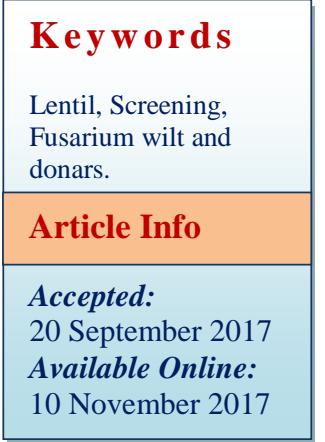

Fusarium wilt is major disease in Central India, the major lentil growing region of country. The disease is soil borne causing huge loss and development of wilt resistant varieties is most effective means of controlling this disease. Highly resistant sources of wilt in lentil have not been reported from the Indian lentil breeding programme. Ninety three lentil accessions including twelve varieties, six ICARDA germplasm lines and seventy five advanced breeding lines were evaluated in field and controlled conditions against wilt. Field screening was carried out at RKVV, Sehore (hot spot) using infector row technique. Based on field and controlled condition screening- IG 69549 and IG 70238 have been identified as highly resistant genotypes. These can be used in hybridization programme for wilt resistance breeding and studying the inheritance of wilt resistance in lentil.

\section{Introduction}

Lentil (Lens culinaris Medik) ranks third in the world after chickpea and pea (FAO 2015). It is considered as one of the oldest domesticated crop in the Near East based on the archaeological evidence (Cubero, 1981; Zohary and Hopf, 1973) and is grown as an important food source over the last 8,000 years (Dhuppar et al., 2012; Oplinger et al., 1990). Lentil is an annual, autogamous, diploid crop $(2 n=14)$ with genome size of approximately $4 \mathrm{Gbp}$ in its haploid component (Arumuganathan and Earle, 1991). Lentil is planted as rotational crop for deriving ecological and environment benefits by improving rhizosphere diversity through biological nitrogen fixation increase in fertility of soil, carbon sequestration, and by management of diseases, weeds and insect pests (Kumar et al., 2013). It is an economical source of proteins, carbohydrates, minerals and fiber for resource poor. The major lentil producing countries are Australia, North America, Western Asia, the Middle East, Nepal, China, Ethiopia, Syria, Bangladesh and India (FAOSTAT, 2014). In India, main lentil growing states are Madhya Pradesh, Bundelkhand region of Uttar Pradesh and Bihar. The global cultivated area of lentil is 
around 4.34 million hectares producing 4.95 million tons of production with an average production of $1140 \mathrm{~kg} / \mathrm{ha}$ (FAOSTAT, 2014). In India lentil was grown in 1.89 mha with production of $1.13 \mathrm{mt}$ with an average production of $598 \mathrm{~kg} / \mathrm{ha}$ during 2013-14. However, yield of lentil remais low due to biotic and abiotic stresses. Biotic stresses such as fusarium wilt (Fusarium oxysporum f.sp. lentis), ascochyta blight (Ascochyta lentis), stemphylium blight (Stemphylium botryosum), anthracnose (Colletotrichum truncatum), root rot (Rhizoctonia solani), rust (Uromyces viciae-fabae), white mold (Sclerotinia sclerotiorum) and collar rot (Sclerotiun rolfsii), (Kumar et al., 2013; Sharpe et al., 2013) affect lentil and cause severe yield loss.

Among them Fusarium wilt caused by Fusarium oxysporum f.sp. lentis is one of the major disease affecting lentil all over the world (Bayaa et al., 1998; Khare 1981). It was first reported from Hungary (Fleischmann, 1937) for the first time, and later on from many countries including India (Padwick, 1941), USA (Wilson and Brandsberg, 1965), USSR (Kotava et al., 1965), Syria (Bayya et al., 1986) and Turkey (Bayya et al., 1998). Globally wilt is considered as the most harmful soil borne disease of lentil (Khare, 1981; Bayya et al., 1998). Fusarium oxysporum f. sp. lentis Vasudeva and Srinivasan affect lentil at every growth stage like seed, seedling, flowering and at crop maturity in stem and root which causes seed rot, stem rots, damping off, wilt and root (Khare et al., 1979; Vasudeva and Srinivasan, 1952). Warm and dry conditions are the most ideal condition for the proliferation of the disease (Bayaa and Erskine 1990). In India, fusarium wilt is the major factor limiting lentil production in the states of Uttar Pradesh, Madhya Pradesh, Himachal Pradesh, Bihar, West Bengal, Assam, Rajasthan, Haryana and Punjab
(Agrawal et al., 1993; Chaudhary et al., 2009; 2010). In India, the incidence of this disease has been reported at seedling, flowering and pod stages at temperature $25^{\circ} \mathrm{C}$ or above (Kannaiyan and Nene, 1976).

Disease management is required to ensure the stable lentil production. Application of fungicide is one of the solutions to overcome this problem but field applications is not feasible due to the expense required and technical difficulty in infusing chemicals into the soil (Taylor et al., 2007). The most sustainable and effective solution to this problem is the development of resistant cultivars (Bayaa et al., 1995; Kraft et al., 2000).

Lentil germplasm can be screened in fields with high levels of natural inoculum of Fusarium oxysporium f.sp. lentis (Kraft et al., 1994, Bayaa et al., 1994). Field screening has limitations such as, confounding effect of drought and other root rot pathogens. Hence screening under controlled conditions in glasshouse is required. High level of wilt resistance has not been reported. The released varieties exhibit variation for resistance. Stable sources are required for breeding wilt resistant varieties. Hence this study was carried out with specific objective of identifying lentil genotypes resistant to Fusarium oxysporum f.sp. lentis through field and green house screening.

\section{Materials and Methods}

Ninety three genotypes of lentil from various parts of India and Mediterranean region were screened against fusarium wilt in wilt sick plot during 2015/16 crop season at hot spot. The field screening was carried out RAK, Sehore, Madhya Pradesh (Central Zone; $23^{\circ}$ $11^{\prime} \mathrm{N} 77^{\circ} 04^{\prime} \mathrm{E} 457 \mathrm{masl}$ ) and screening under controlled condition was carried out at Indian Agricultural Research Institute, New Delhi in 
greenhouse condition. The genotypes used in this study along with their origin are listed in Table 1. Screening for resistance to lentil wilt must take into account two factors: the varied timing of symptom expression among genotypes and the uneven and patchy distribution of the disease in the field. For effective and efficient screening for resistance to soil borne pathogens such as Fusarium spp. simulation of natural soil and environmental conditions and uniform inoculum load across all the plants of test genotypes to discriminate between resistant and susceptible genotypes (Porta-Puglia and Aragona, 1997) is necessary.

\section{Screening under wilt sick plot}

The method for screening in wilt sick plot has been described by Bayaa and Erskine (1990), Bayaa et al., (1995, 1997), and Eujayl et al., (1998). The experimental material for the present study comprised of 93 lentil genotypes. The field experiment was laid out in Randomized Complete Block Design (RCBD) with three replications per entry (3 rows per replication) with plant distance of 5 $\mathrm{cm} \times 25 \mathrm{~cm}$ and row length of 4 metre. Susceptible cultivar 'L 9-12' was planted between every two rows of genotypes screened as infector / spreader row. Observations on wilt incidence were recorded at fortnightly interval just after appearance of the disease.

\section{Greenhouse screening}

Laboratory and glasshouse screening techniques for resistance to wilt of lentil have been described in previous reviews (Bayaa et al., 1994; Khare et al., 1993; Kraft et al., 1994). The seeds were superficially sterilized in $3 \%$ sodium hypochlorite for $3 \mathrm{~min}$, then washed in sterile water and then germinated in towel paper for 10 days. Inoculum of pure culture of Fusarium oxysporium, isolated from naturally wilt infected lentil plants was used for multiplication. Single spore culture of $F$. oxysporium was multiplied on $100 \mathrm{~g}$ of 9:1 sand: lentil meal medium for 15 days at $28-30{ }^{\circ} \mathrm{C}$. Two hundred gram of these inoculums was mixed well with $2 \mathrm{~kg}$ autoclaved soil and placed in one $15 \mathrm{~cm}$ plastic pots. The 10-day-old uprooted seedlings were washed under water to remove soil particles. Root tips approximately $0.6 \mathrm{~cm}$ long were cut to facilitate the entry of pathogen in roots. The roots of the seedlings were then immersed in the spore suspension $(5 \times 106$ conidia $\mathrm{ml}-1)$ for $5 \mathrm{~min}$ to enable conidia to stick to the roots. Inoculated seedlings were transplanted into a mixture of equal parts of sterile soil, sand, peat and perlite which had been potted and preirrigated 2 days previously. Seedlings were irrigated after their planting in pots, and incubated at $25 \pm 3^{\circ} \mathrm{C}$.

The appearance of disease symptoms, the percentage of dead plants was recorded following the method proposed by Bayaa and Erskine (1990).The following formula was used to calculate wilt disease incidence

Disease incidence $(\%)=$ Total number of plants examined/ No. of plants infected $\times 100$

\section{Results and Discussion}

Wilt disease of lentil is caused by Fusarium oxysporium f. sp. lentis. In this study lentil genotypes were screened for resistance to fusarium wilt under controlled and field conditions. Several accessions with high level of resistance under both controlled and field conditions were identified.

\section{Reactions of lentil promising lines against Fusarium wilt under field conditions}

Field screening was carried out against fusarium wilt in sick plot. 
Table.1 The list of materials used in the study along with its source

\begin{tabular}{|c|c|c|c|}
\hline S. No. & Genotype & Source & Pedigree \\
\hline 1 & L4721 & IARI, New Delhi & - \\
\hline 2 & L4712 & IARI, New Delhi & - \\
\hline 3 & L4717 & IARI, New Delhi & ILL $7617 \times 91516$ \\
\hline 4 & L4076 & IARI, New Delhi & PL234 × PL 639 \\
\hline 5 & L4715 & IARI, New Delhi & - \\
\hline 6 & L4590 & IARI, New Delhi & - \\
\hline 7 & L4716 & IARI, New Delhi & - \\
\hline 8 & L4718 & IARI, New Delhi & - \\
\hline 9 & L4719 & IARI, New Delhi & - \\
\hline 10 & L4147 & IARI, New Delhi & (L $3875 \times$ P4)PKVL1 \\
\hline 11 & L4720 & IARI, New Delhi & - \\
\hline 12 & L4714 & IARI, New Delhi & - \\
\hline 13 & L4713 & IARI, New Delhi & - \\
\hline 14 & L4709 & IARI, New Delhi & - \\
\hline 15 & $\mathrm{~L} 4710$ & IARI, New Delhi & L4603 × PL406 \\
\hline 16 & L4593 & IARI, New Delhi & - \\
\hline 17 & L4711 & IARI, New Delhi & - \\
\hline 18 & L4592 & IARI, New Delhi & - \\
\hline 19 & L4708 & IARI, New Delhi & - \\
\hline 20 & L 9-12 & IARI, New Delhi & - \\
\hline 21 & L1373 & IARI, New Delhi & - \\
\hline 22 & L4739 & IARI, New Delhi & - \\
\hline 23 & L4737 & IARI, New Delhi & - \\
\hline 24 & L4730 & IARI, New Delhi & - \\
\hline 25 & L4726 & IARI, New Delhi & - \\
\hline 26 & L4727 & IARI, New Delhi & - \\
\hline 27 & $\mathrm{~L} 4117$ & IARI, New Delhi & - \\
\hline 28 & LL1320 & PAU, Ludhiana & LL158 $\times$ DPL15 \\
\hline 29 & LL1316 & PAU, Ludhiana & DPL15 × L967 \\
\hline 30 & L1318 & IARI, New Delhi & - \\
\hline 31 & IG 69549 & ICARDA, Aleppo, Syria & - \\
\hline 32 & IG 70238 & ICARDA, Aleppo, Syria & - \\
\hline 33 & IG 71487 & ICARDA, Aleppo, Syria & - \\
\hline 34 & ILL 10916 & ICARDA, Aleppo, Syria & - \\
\hline 35 & ILL 10921 & ICARDA, Aleppo, Syria & - \\
\hline 36 & ILL 10965 & ICARDA, Aleppo, Syria & - \\
\hline 37 & PL6-9 & Pantnagar & - \\
\hline 38 & DPL15 & IIPR, Kanpur & PL406 × L4076 \\
\hline 39 & SLC101 & RARS, Sahillongani & $\begin{array}{l}\text { Pure line selection from } \\
\text { 'Chirarg Local' }\end{array}$ \\
\hline 40 & PL178 & Pantnagar & PL $5 \times$ DPL 15 \\
\hline 41 & IPL332 & IIPR, Kanpur & IPL517 × DPL62) DPL62 \\
\hline
\end{tabular}




\begin{tabular}{|c|c|c|c|}
\hline 42 & HUL57 & Varanasi & Mutant of HUL-11 \\
\hline 43 & PL175 & Pantnagar & PL02×DPL58 \\
\hline 44 & PL157 & Pantnagar & PL02 $\times$ DPL58 \\
\hline 45 & KLS13-3 & - & - \\
\hline 46 & KLB13-6 & CSA, Kanpur & KLB08-4 × KLB 303 \\
\hline 47 & IPL334 & IIPR, Kanpur & $\begin{array}{l}(\text { ILL } 6002 \times \text { DPL 62) } \times \\
\text { JL1 }\end{array}$ \\
\hline 48 & IPL222 & IIPR, Kanpur & - \\
\hline 49 & IPL227 & IIPR, Kanpur & $98 / 155 \times$ Pant L 5 \\
\hline 50 & IPL335 & IIPR, Kanpur & - \\
\hline 51 & KLB14-12 & CSAUT, Kanpur & KLB345 × KLB303 \\
\hline 52 & IPL331 & IIPR, Kanpur & - \\
\hline 53 & $\begin{array}{l}\text { RKL1003- } \\
\text { 21C }\end{array}$ & ARS, Kota & Mutant of DPL 62 \\
\hline 54 & IPL81 & IIPR, Kanpur & PL639 $\times \mathrm{K}-75$ \\
\hline 55 & PL194 & Pantnagar & PL02 $\times$ DPL15 \\
\hline 56 & VL524 & Almora & VL $501 \times$ VL 502 \\
\hline 57 & RVL13-5 & Sehore & JL3 $\times$ DPL 62 \\
\hline 58 & RKL14-26 & ARS, Kota & RKL1001 × KLB339 \\
\hline 59 & RVL13-7 & Sehore & JL $1 \times$ Black Masara \\
\hline 60 & VL148 & Almora & DPL15 × L4076 \\
\hline 61 & VL525 & Almora & VL120 $\times$ DPL 15 \\
\hline 62 & DKL37 & Dhaulakaun & DPL-6 $\times$ PL-5 \\
\hline 63 & RLG195 & RARI, Durgapura & IPL $313 \times$ PL5 \\
\hline 64 & IPL315 & IIPR, Kanpur & - \\
\hline 65 & PL-165 & Pantnagar & DPL $15 \times$ PL639 \\
\hline 66 & $\begin{array}{l}\text { RKL24C- } \\
59\end{array}$ & ARS, Kota & Mutant of DPL62 \\
\hline 67 & DPL62 & IIPR, Kanpur & JL1 $\times$ LG171 \\
\hline 68 & IPL329 & IIPR, Kanpur & KL178 $\times$ DPL62 \\
\hline 69 & IPL220 & IIPR, Kanpur & $\begin{array}{l}(\text { DPL44 } \\
\text { DPL58 }\end{array}$ \\
\hline 70 & KLS14-1 & CSAU, Kanpur & KLS9-3 $\times$ KLS133 \\
\hline 71 & IPL576 & IIPR, Kanpur & - \\
\hline 72 & NDL14-22 & Faizabad & NDL $1 \times$ PusaVabhav \\
\hline 73 & LL1374 & PAU, Ludhiana & IPL406 × FLIP2004-7L \\
\hline 74 & IPL406 & IIPR, Kanpur & DPL $35 \times$ EC $157634 / 382$ \\
\hline 75 & $\begin{array}{l}\text { RKL12- } \\
\text { 11E-119 }\end{array}$ & ARS, Kota & Mutant of DPL62 \\
\hline 76 & IPL228 & IIPR, Kanpur & VKS16/21 × DPL62 \\
\hline 77 & PL191 & Pantnagar & DPL $15 \times$ LL992 \\
\hline 78 & IPL321 & IIPR, Kanpur & K75 × DPL62 \\
\hline 79 & NDL14-21 & Faizabad & NDL $1 \times$ PANT L 4 \\
\hline 80 & IPL325 & IIPR, Kanpur & - \\
\hline 81 & RVL11-6 & Sehore & JL3 $\times$ DPL 62 \\
\hline
\end{tabular}




\begin{tabular}{|l|l|l|l|}
\hline 82 & RKL603-1 & ARS, Kota & $\begin{array}{l}\text { L 4682 } \times \text { DPL 62 } \\
\text { VL126 }\end{array}$ \\
\hline 83 & VL149 & Almora & $\begin{array}{l}\text { VL 105) } \\
\text { VL }\end{array}$ \\
\hline 84 & DKL14-20 & Dhaulkuan & - \\
\hline 85 & IPL316 & IIPR, Kanpur & Sheore 74-3 $\times$ DPL 58 \\
\hline 86 & PL172 & Pantnagar & PL 5 $\times$ DPL 15 \\
\hline 87 & KLS218 & CSAU, Kanpur & KLS133 × LG362 \\
\hline 88 & IPL533 & IIPR, Kanpur & - \\
\hline 89 & RLG192 & RARI, Durgapura & RLG32 $\times$ L4076 \\
\hline 90 & IPL330 & IIPR, Kanpur & KL 178 $\times$ DPL 62 \\
\hline 91 & RL3-5 & IGKV, Raipur & Selection from germplasm \\
\hline 92 & PL192 & Pantnagar & - \\
\hline 93 & $\begin{array}{l}\text { Sehore 74- } \\
3\end{array}$ & JNKVV, Jabalpur & - \\
\hline
\end{tabular}

Table.2 Reactions of lentil genotypes against Fusarium wilt

\begin{tabular}{|c|c|c|c|}
\hline $\begin{array}{l}\text { Rating } \\
\text { scale }\end{array}$ & Reaction & Field screening & Glasshouse screening \\
\hline 1 & $\begin{array}{l}\text { Resistance } \\
((\leq 1 \%)\end{array}$ & $\begin{array}{l}\text { IG 69549, IG 70238, IG 71487, ILL 10916, } \\
\text { ILL 10921, ILL10965 }\end{array}$ & IG 69549, IG 70238 \\
\hline 3 & $\begin{array}{l}\text { Moderately } \\
\text { resistant } \\
(2-10 \%)\end{array}$ & $\begin{array}{l}\text { L4712, L4713, L4714, L4717, L4719, L4720, } \\
\text { LL1374, IPL334, PL175, DPL15 }\end{array}$ & IG 71487, ILL 10916, ILL 10921, ILL 10965 \\
\hline 5 & $\begin{array}{l}\text { Moderately } \\
\text { susceptible } \\
(11-50 \%)\end{array}$ & $\begin{array}{l}\text { L4592, L4593, L4709, L4710, L4711, L4715, } \\
\text { IPL321, IPL332, IPL576, PL178, PL192, } \\
\text { HUL57 }\end{array}$ & $\begin{array}{l}\text { L4713, L4714, L4719, DPL15, IPL334, } \\
\text { PL175, L4720, LL1374, L4708, L4593 }\end{array}$ \\
\hline 7 & $\begin{array}{l}\text { Susceptible } \\
(21-50 \%)\end{array}$ & $\begin{array}{l}\text { L1318, L1373, L4076, L4117, L4590, L4708, } \\
\text { L4716, L4718, L4721, L4726, L4727, L4737, } \\
\text { L4739, LL1320, IPL220, IPL222, IPL227, } \\
\text { IPL228, IPL315, IPL325, IPL335, IPL406, } \\
\text { IPL533, PL157, PL172, PL191, PL194, } \\
\text { RKL24C-59, RKL603-1, RKL14-26, } \\
\text { RLG195, VL524, NDL14-21, NDL14-22, } \\
\text { KLB13-6, DKL14-20, DPL62 }\end{array}$ & $\begin{array}{l}\text { L4709, L4710, PL178, PL192, HUL57, } \\
\text { IPL321, IPL332, IPL576, L1318, L1373, } \\
\text { L4076, L4117, L4590, L4592, L4711, L4712, } \\
\text { L4715, L4716, L4717, L4721, L4726, L4727, } \\
\text { L4737, L4739, LL1320, IPL220, IPL222, } \\
\text { IPL227, IPL228, IPL315, IPL325, IPL335, } \\
\text { PL406, IPL533, DPL62, DKL14-20, RKL14- } \\
\text { 26, RKL24C-59, RKL603-1, RLG195, } \\
\text { KLB13-6, VL524, PL157, PL172, PL191, } \\
\text { PL194, NDL14-21, NDL14-22 }\end{array}$ \\
\hline 9 & $\begin{array}{l}\text { Highly } \\
\text { susceptible } \\
(>50 \%)\end{array}$ & $\begin{array}{l}\text { L 9-12, L4147, L4730, LL1316, Sehore 74-3, } \\
\text { IPL81, IPL316, IPL329, IPL330, IPL331, } \\
\text { PL6-9, PL-165, KLS14-1, KLS13-3, } \\
\text { KLS218, RLG192, RL3-5, KLB14-12, } \\
\text { RKL1003-21C, RKL12-11E-119, RVL11-6, } \\
\text { RVL13-5, RVL13-7, VL148, VL149, VL525, } \\
\text { DKL137, SLC101 }\end{array}$ & $\begin{array}{l}\text { L4718, L 9-12, LL1316, L4147, L4730, Sehore } \\
\text { 74-3, RLG192, IPL81, IPL316, IPL329, } \\
\text { IPL330, IPL331, RL3-5, PL-165, PL6-9, } \\
\text { KLS13-3, KLS14-1, KLS218, KLB14-12, } \\
\text { RKL1003-21C, RKL12-11E-119, RVL11-6, } \\
\text { RVL13-5, RVL13-7, VL148, VL149, VL525, } \\
\text { DKL37, SLC101 }\end{array}$ \\
\hline
\end{tabular}


The studied genotypes were rated on rating scale (1-9)

\author{
Rating Scale \\ [Wilt incidence percent] \\ $11 \%$ or less plants wilted \\ $32-10 \%$ plants wilted \\ $511-20 \%$ plants wilted \\ $721-50 \%$ plants wilted \\ 9 Above $50 \%$ plants wilted
}

Reaction

Resistant

Moderately Resistant

Moderately Susceptible

Susceptible

Highly Susceptible
The uniform distribution of inoculum in sick plot was evident from $100 \%$ mortality of L 912 (infector row).Out of 93 genotypes screened only six genotypes IG 69549, IG 70238, IG 71487, ILL 10916, ILL 10921, ILL 10965 showed the resistance expression while ten genotypes 4712, L 4713, L 4714, L 4717, L 4719, L 4720, LL 1374, IPL 334, PL 175, DPL 15 expressed the moderate resistant reaction in field condition. ICARDA genotypes expressed relatively higher resistance in comparison to Indian genotypes. Whereas L 4592, L 4593, L 4709, L 4710, L 4711, L 4715, IPL 321, IPL 332, IPL 576, PL 178, PL 192, HUL 57 exhibited moderate susceptibility, while genotypes L 1318, L 1373, L 4076, L 4117,L 4590, L 4708,L 4716, L 4718, L 4721, L 4726, L 4727, L 4737, L 4739, LL 1320, IPL 220, IPL 222, IPL 227, IPL 228, IPL 315, IPL 325, IPL 335, IPL 406, IPL 533, PL 157, PL 172, PL 191, PL 194,RKL 24C-59, RKL 603-1, RKL 14-26, RLG 195, VL 524,NDL 14-21, NDL 14-22, KLB 13-6, DKL 14-20, DPL 62, were revealed susceptibility to wilt.

The genotypes L 9-12, L 4147, L 4730, LL 1316, Sehore 74-3, IPL 81, IPL 316, IPL 329, IPL 330, IPL 331, PL 6-9, PL 165, KLS 14-1, KLS 13-3, KLS 218, RLG 192, RL3-5, KLB14-12, RKL1003-21C, RKL12-11E-119, RVL11-6, RVL13-5， RVL13-7， VL148, VL149, VL525, DKL137, SLC101 expressed moderate to very high susceptibility reaction against the fusarium wilt. Bhat et al., (2003) and De et al., (2003) have also identified fusarium wilt resistant germplasm line in lentil based on field screening.

Reactions of lentil genotypes against Fusarium wilt under greenhouse condition

Under the controlled greenhouse condition two genotypes IG 69549 and IG 70238 exhibited resistance reaction while, genotypes IG 71487, ILL 10916, ILL 10921, ILL 10965 exhibited moderate resistance reaction. Genotypes L4713, L4714, L4719, DPL15, IPL334, PL175, L4720, LL1374, L4708, and L4593 revealed moderate susceptibility. The genotypes L4709, L4710, PL178, PL192, HUL57, IPL321, IPL332, IPL576, L1318, L1373, L4076, L4117, L4590, L4592, L4711, L4712, L4715, L4716, L4717, L4721, L4726, L4727, L4737, L4739, LL1320, IPL220, IPL222, IPL227, IPL228, IPL315, IPL325, IPL335, PL406, IPL533, DPL62, DKL14-20, RKL14-26, RKL24C-59, RKL603-1, RLG195, KLB13-6, VL524, PL157, PL172, PL191, PL194, NDL14-21, NDL14-22 expressed susceptible reaction. The genotypes L4718, L 9-12, LL1316, L4147, L4730, Sehore 74-3, RLG192, IPL81, IPL316, IPL329, IPL330, IPL331, RL3-5, PL-165, PL6-9, KLS13-3, KLS14-1, KLS218, KLB14-12, RKL1003-21C, RKL12-11E-119, RVL11-6， RVL13-5， RVL13-7， VL148, VL149, VL525, DKL37, SLC101 revealed high susceptibility against the fusarium wilt (Table 2). The significant information about host-pathogen biology and interaction is necessary for successful screening. The use of 
well-established tests for both field and greenhouse screening help in identification and selection of donors for wilt resistance. The screened resistance genotypes would have immense potential for use as resistance sources for breeding wilt resistant lentil varieties and cloning of the resistant genes through differential display expression analysis in future research programs.

\section{References}

Agrawal, S.C., Singh, K. and Lal, S.S. 1993. Plant protection of lentil in India. In: Lentil in South Asia (eds. W. Erskine and M.C. Saxena). ICARDA, Aleppo, Syria. Pp. 147-165.

Bayaa, B., Kumari, S.G., Akkaya, A., Erskine, W, Makkouk, K.K., Turk, Z. and Ozberk, I. 1998. Survey of major biotic stresses of lentil in Southeast Anatolia. Turkey. Phytonathol. Medit. 37: 88-95.

Bayaa, B. and Erskine, W.1990.Disease of lentils In.The Pathology of food and pasture legumes (eds. DJ. Allon and J.M. Lenne) Commonwealth Agriculture Bureau International Wallingford, U.K.: Pp. 423-471

Bayaa, B. and Erskine, W.1990.Screening technique for resistance to vascular wilt in lentil. Arab J. Plant Prot., 8:30-33

Bayaa, B., Erskine, W and Hamdi, A.1994. Evauating different methods for screening lentil germplasm for resistance to lentil wilt caused by Fusarium oxysporium f.sp. lentis. Arab J. Plant Prot., 12:83-91

Bayaa, B., Erskine, W. and Singh, M. 1997.Screening lentil for resistance to Fusarium wilt: methodology and sources of resistance. Euphytica. 98: 69-74.

Bayaa, B., Erskine, W. and Khoury, L.1986. Survey of wilt damage on lentil in Northwest Syria. Arab J. Plant Prot.,
4:118-119

Bayaa, B., Erskine,W. and Hamdi, A. 1995. Evaluation of a wild lentil collection for resistance to vascular wilt.Genet. Resour. Crop Evol., 42:231-235

Bhat, N.A., Beig, M.A. Maheshwari, S.K. and Masoodi, S.D. 2006. Screening and yield of Lentil germplasms as influenced by Fusarium wilt. Ann. Pl. Protec. Sci. 14: 139-141.

Chaudhary, R.G., Dhar V. and Singh, R.K.2009.Association of fungi with complex of lentil at different crop growth stages and moisture regimes. Arch. Phytopathol. Plant Prot. 42:340343.

Chaudhary, R.G., Saxena, D.R. Dhar V. and Singh, R.K. 2010. Prevalence of wilt root rots and their associated pathogens at reproductive phase in lentil. Phytopathol. Plant Prot. 43:996-1000

De, R.K., P.P. Dwivedi and UditNarain. 2003. Biological control of lentil wilt caused by Fusarium oxysporum f. sp. lentil. Ann. Pl. Protec. Sci. 11: 46-52.

Dhingra, O.D. and J.B. Sinclair, 1985. Basic Plant Pathology Methods. CRC Press, Boca Raton, Florida.

Eujayl,.I, Erskine, W., Bayaa, B., Baum, M. and Pehu E. 1998. Fusarium vascular wilt in lentil: Inheritance and identification of DNA markers for resistance. Plant Breed. 117:497-499

\section{FAOSTAT:} http://faostat3.fao.org/home/index.html \#DOWNLOAD.

Fleischmann, A.1937.Observations on lentil wilt. Pflanzenbau, 14:49-56

Khare, M.N., Agrawal, S.C., Dhingra, O.D. and Kushwaha, L.S.1975.Variability in the growth of eight strains of Fusarium oxysporium f.sp.lentis on different solid media. Indian Phytopathol. 28:126-128

Khare, M.N., Bayaa, B. and Beniwal, S.P.S. 1993. Selection methods for disease resistance in lentil. In: K.B. Singh. \& 
M.C. Saxena (Eds.), Breeding for StressTolerance in Cool-Season Food Legumes, pp 107-122. Wiley, Chichester, UK.

Kraft, J.M., Haware, M.P., Jim'enez-Diaz, R.M., Bayaa, B. and Harrabi, M. 1994. Screening techniques and sources of resistance to root rots and wilts in cool season food legumes. Euphytica.73: 2739.

O.W. Padwick. 1941. Report of the imperial mycologist. Scientific Report: 193940.Imperial Agricultural Research Institute, New Delhi, India. Pp. 94-101.

Porta-Puglia, A. \& M. Aragona.1997. Improvement of grain legumes-General part: Diseases Field Crop Res., 53: 17
30.

Porta-Puglia, A., Bernier, C.C., Jellis, G.J., Kaiser, W.J. and Reddy, M.V. 1994. Screening techniques and sources of resistance to foliar diseases caused by fungi and bacteria in cool-season food legumes. Euphytica73: 11-25.

Vasudeva, R.S. and Srinivasan, K.V.1952. Studies on the Wilt disease of Lentil (Lens esculenta Moench). India Phytopath. 5: 23-32.

Wilson, V.E. and Brandsberg, J.1965.Fungi isolated from diseased lentil seedlings in 1963-64. Plant Disease Reporter, 49:660-662.

\section{How to cite this article:}

Jitendra Kumar Meena, Akanksha Singh, H.K. Dikshit, G.P. Mishra, M. Aski, N. Srinivasa, Soma Gupta, Deepa Singh and Aparna Tripathi. 2017. Screening of Lentil (Lens culinaris Medikus sub sp. culinaris) Germplasm against Fusarium Wilt (Fusarium oxysporum f. sp. lentis). Int.J.Curr.Microbiol.App.Sci. 6(11): 2533-2541. doi: https://doi.org/10.20546/ijcmas.2017.611.298 